\title{
The Manifestation of Occupational Stress in the Teaching Profession: The Unheeded Voices of Teachers
}

\author{
Mncedisi C. Maphalala \\ Department of Curriculum \& Instructional Studies, \\ College of Education, University of South Africa, \\ E-mail:mphalmc@unisa.ac.za
}

\section{Doi:10.5901/mjss.2014.v5n1p77}

\section{Abstract}

Numerous studies have established that teaching can be a stressful profession and that stress may affect career motivation and diminish effectiveness and job satisfaction of many loyal and gifted teachers. Van der Westhuisen (1991) observes that the increasing demands made on the schools and teachers have led to an alarming escalation of stress and professional burnout as career risks for those in the teaching profession. A major concern with occupational stress in the teaching profession is that prolonged experience of stress can precipitate both mental and physical ill-health (Walker \& Cole, 1989:28). The widespread concern regarding occupational stress in teaching has led many researchers to focus on this area. Furthermore, there has been an increasing recognition of the link between mental and physical health and occupational stress, and indeed concern to improve the working lives of teachers (Williams \& Gersch, 2004). This sought to investigate the sources of occupational stress amongst primary school teachers. The sample consisted of 168 teachers from primary schools in KwaZulu Natal province, South Africa. Data were collected using a questionnaire. The study reveals that teaching stressors which the teachers found stressful, in order of most to least stressful, were curriculum changes, work load pressures, job insecurity, poor relationship with colleagues, reward and recognition, learners discipline problems, poor rapport with management and role ambiguity. In terms of factors associated with teacher stress, the results showed that a combination of internal and external factors were associated with teacher stress. In terms of internal factors, organisational stressors and classroom stressors were associated with teacher stress. In terms of external stressors minimal general life stressors were also found to be associated with teacher stress. The areas which teachers viewed as most stressful were policy changes, timework load pressures and classroom discipline.

Keywords: Occupational stress; Stressor; Job satisfaction; Motivation; Job insecurity, role ambiguity

\section{Background to the Study}

Stress is an organisational problem, which can affect persons in any social environment, be it work place, home or church. Like other people in their organisations, teachers are prone to stress because of the nature of their work. The causes of stress can either be internal or external to the individual. Furthermore both internal and external circumstances to what happens in the classroom could make teaching a stressful experience. There are decisions made regarding the process or reorganisation of education and changes in the instructional process. Such initiatives may have a negative effect on the teacher. Farber (1983:281) states that it is often the case that changes being imposed on the school and the teacher, are not those which the teacher believes are in the interest of learners, his or her effectiveness or job satisfaction. Not only are the decisions and policies often demanding from the teachers's point of view, but he or she may have had little input into and influence on the nature of these decisions and changes of an attitudinal and behavioral nature which may place demands on teachers. According to Van der Westhuisen (1991:327), the increasing demands made on the schools and teachers have led to an alarming escalation of stress and professional burnout as career risks for those in the teaching profession. A major concern with teacher stress in schools is that prolonged experience of stress can precipitate both mental and physical ill-health (Walker \& Cole, 1989:28).

In schools, occupational stress is a problem because of its effect on job performance. This can include teachers' leave of absence taken to cope with stress, resultant ill-heath, a lowered level of job satisfaction and commitment and impaired quality of classroom teaching (Kyriacou, 1998). In the latter case the teacher's rapport with the learners and colleagues can easily be affected as he or she experiences high levels of stress. Teaching makes immense demands on the mind and feelings of the teacher. There is a constant danger of role over-load and the teacher must be aware of personal stress (Laar, 1989:42). As Farber (1991:44) observes, it is to the teachers that we entrust our children and thus 
our future". Such statements may put undue pressure on the teachers, and as teachers share the responsibility with a multiplicity of role players, role conflict is a distinct possibility.

Research has shown that the incidents of stress among teachers emanate from break-down of discipline in the school, role ambiguity and conflict, lack of rewards and recognition, poor interpersonal relationships with colleagues, work overload and job insecurity (Walker and Cole:1989:290; Telfer \& Swannt: 1986:57; Glaxton 1989:43; Williams \& Gersh, 2004; Sutherland \& Cooper ,2000. Our education system has placed the educational and emotional welfare of learners first and the true needs and morale of the teachers who deliver this service seem to be negated. With transformation taking place at a high speed, no measures have been put in place to assist teachers to cope with the new challenges that they are facing. This could promote the escalation of stress in the teaching profession. In turn, stress may affect career motivation and diminish effectiveness and job satisfaction of many loyal and gifted teachers. It is for this reason that this phenomenon cannot be ignored hence, the present research project. This study specifically investigated the manistification teacher stress in primary schools in KwaZulu Natal province, South Africa.

\section{Aims of the study}

This study sought to:

- Ascertain the main sources of stress amongst the primary school teachers.

- Determine whether teachers' biographical factors namely age, gender, educational level and marital status have any influence on the incidence of teacher stress.

- Conduct an empirical investigation into the nature of stress experienced by teachers in schools.

\section{Research methodology}

The study focused on Post Level 1 teachers in fifteen primary schools in KwaZulu Natal. This study uses the descriptive approach into data collection. The descriptive approach is chosen because of its relevance in describing systematically the facts and characteristics of an area of interest, factually and accurately. Of the various types of descriptive approaches, this study used the survey. According to Cohen and Manion (1989:97) surveys gather data at a particular point in time with the intention of (a) describing the nature of existing conditions, or (b) identifying standards against which existing conditions can be compared, or (c) determining the relationships that exist between specific events. A total number of 168 teachers participated in the study. The female teachers constituted $71 \%$ of the population and the male teachers $29 \%$.

This study used a questionnaire for collecting data. The questionnaire was designed for teachers and focused on demographic data which included teaching experience, qualifications, gender and employment status (temporary or permanent). Section B focused on stress in relation to work as well as stress outside the working environment that might put pressure on the teachers.

\section{Results}

Informed by the literature, the researcher isolated the following variables as possible sources of stress amongst primary schools teachers: ( a) Curriculum, (b) Time pressure and Workload, (C) Learners (d) Job Insecurity (e) Role Ambiguity (f) Rapport between the teacher and the management (h) Relationship with colleagues (i) Lack of rewards and Recognition (j) Other stressors associated with teacher stress

The analysis and interpretation of data for this research question were made possible with the use of Life Stress Scale (Fontana and Abouserie, 1993:267). Altogether, there were 45 items that were categorised into 9 variables. The total stress scores yielded by the items in the questionnaire were categorised into five advisory stress levels namely "no stress" (never), Low stress (seldom), "moderate stress" (sometimes), "high stress" (usually), "very high stress" (always). The responses to the questionnaire were distributed among the five categories. Table 1 (Appendix A) presents the results, which are subsequently discussed under specified sub-headings in accordance with the research question.

\subsection{Biographical information of the participants}

Table 1 (appendix A) illustrates, that a significant number of teachers, (37 \%) ranged between the ages of 30 and 39 ; A significant number, (27\%) fell below 30 years of age; $23 \%$ ranged between 40 and 49 years of age; and $13 \%$ were aged 
between 50 and 59 and no teachers were 60 years or above. This may suggest that most teachers in this age group occupy senior postitions while others opt for early retirement or alternative occupation.

Regarding gender distribution Table 1 (appendix A) shows that $71 \%$ of the respondents were female and $29 \%$ were male. The high percentage of females could be attributed to the fact that women dominated the primary school sector and that lower primary schools in particular constitute an exclusive feminine domain. With regard to teaching experience $42 \%$ of the respondents had teaching experience of 11 years and above; $36 \%$ had teaching experience of 6 to 10 years; and $22 \%$ had teaching experience of between 0 and 5 years. The small fraction of young and relatively inexperienced teachers suggests that the rate of employing new teachers may be low.

The Table also shows that $7 \%$ of the respondents had matric (Grade 12) as the highest qualification and $56 \%$ held first degrees and $2 \%$ had Honours qualifications. Regarding employment status, permanent teachers constituted $81 \%$ of the total proportion of the respondents and $19 \%$ held temporary posts

\subsection{Curriculum}

The responses with regard to curriculum changes are summarized in table 2 (appendix B). According to table 2,55,8\% of the respondents reported high to very high levels of stress from dealing with curriculum issues and changes whilst $33.1 \%$ of the respondents experienced levels of stress ranging from low to moderate. The other $11,1 \%$ of the respondents did not experience any stress from dealing with curriculum changes and related issues.

There is a feeling among teachers that they have not been properly equipped with skills to implement the ever changing curriculum in South Africa. The highest levels of stress among teachers were caused by the introduction of the new curriculum. The amount of effort required to keep abreast of changes in the assessment and curriculum areas is greater than ever before. A study completed by Smith (2000) indicates that the South African education system characterised by continued change and adaptation, is one of the main sources of stress in teachers. Potgieter (1996) confirms these changes as contributing factors to increasing stress levels in teachers. Potgieter (1996:40) indicates that negative attitudes towards the changing educational environment are the main factor correlating with increased stress experiences. One of the respondents in her study said "Rome was not built in one day... I think changing teachers, changing languages, changing exams, changing names, everything...that's just too much change at once and I think we're battling to keep our heads above water. ..". She further determined that the teachers' negative attitudes were the direct result of change in the education system; dissatisfaction with the change and uncertainty regarding the future.

Any sort of change is a source of stress, although certain changes are clearly more stressful than others. The more changes present in a teacher's environment, and the faster these changes occur, the greater the stress that will be experienced. When a person's surroundings are stable, most people learn to cope with a situation. Yet when there is rapid change, even people who are mentally the healthiest will find it difficult to avoid the impact of the ensuing stress (Cohen, 1991; Hayward, 1994).

\subsection{Time pressure and work overload}

The responses with regard to time pressure and work overload are summarized in table 3 (Appendix C). Table 3 shows that $47,6 \%$ of the respondents reported "high to very high" levels of stress from time pressure and work overload. Stress arising from time pressure and work overload is concerned with having too much to do in little time and work intruding on home life. The table also shows that $38,7 \%$ of the respondents reported low to moderate levels of stress while $13,7 \%$ reported no stress from this area. In the study this area of stress was typified by such items as (having to deal with large classes, having too heavy work load, which cannot be finished during school hours, being unable to meet deadlines and schedules.

The largest direct effect on teacher stress in this category resulted from planning and assessment workload. Grades 1 to 3 teachers had a lesser workload as they assess only three aspects (life skills, numeracy and literacy), whilst grades 5 to 7 teachers carry more workload as they have to assess eight learning areas. With regard to work overload the study revealed that this area was the second highest stressor recorded by the teachers. Stress resulting from work overload could be attributed to the introduction of the new curriculum, understaffing or poor teacher-pupil ratio. Literature describes time demands and workload as one of the biggest contributors to stress (King \& Peart, 1992 \& Brownell, 1997). Cranwell-Ward (1990) states that role overload is pressure that occurs as a result of 'too much- to-do-too-littletime-to-do-it'. Teachers in the high stress group were far more likely to agree that they had too much paperwork, too many deadlines to meet and too little preparation time. 
The study of Wilkinson (1988) indicated that heavy workloads were widely reported and were frequently linked to the time factor. His study established that heavy workloads arose during seasonal peaks of demands when staff attempted to do more in less time. Role conflict was reported to be greatest at times of seasonal peaks of work demands. A major aspect of workload is administrative duties. Excessive paperwork is burdensome and wasteful, because it takes time away from teaching duties per se, and is frustrating because it prevents teachers from pursuing the more satisfying and important aspects of their job. It reduces the role of teachers to that of clerical assistants (Mbokodi, 1995).

\subsection{Learners}

Learner related sources of stress are reflected in table 4 (appendix D). Stress arising from learners is concerned with difficulties encountered when dealing or interacting with learners. This area of stress was represented in the questionnaire by items such as having to deal with indiscipline learners, inadequate disciplinary policy for learners, learners coming to class without the necessary learning material, abolition of corporal punishment and having to deal with learners who are hard to motivate. Table 4 reveals that the majority of the respondents $(52,7 \%)$ fell under the high to very high stress categories as measured by life stress scale. The investigation also revealed that $34,8 \%$ of the respondents reported low to moderate levels of stress. Other respondents $(15,5 \%)$ did not experience any stress from dealing with learners.

According to Smith and Bourke (1992:315) this area of concern is almost universally reported as a major stressor in the teaching profession. The longer serving teachers were found to be less prone to learner-related stress than inexperienced teachers. This may be attributed to the fact that the established teachers may have had ample opportunity to develop skills, over time to foster effective relationships with learners and may have developed effective indiscipline handling techniques. The learner misbehaviors reported by teachers included damaging equipment, distracting others as well as fighting verbally and physically.

This study discovered that breakdown of discipline was one of the causes of stress among teachers. There appears to be a universal agreement that learners were less self-disciplined, in many cases, less respectful of simply because you are a teacher. The main concern of the teachers was that when corporal punishment was abolished there were no effective alternative methods of punishment that were put in place.

The challenge facing the Department of Education and teachers is a paradigm shift from the traditional way of maintaining school and classroom discipline as opposed to the modern and democratic way of discipline maintenance. The Schools Act (1996) makes it clear that corporal punishment may no longer be used in public and independent (private) schools as a means of punishment. In addition, Section 12 of the Constitution states that everyone has the right not to be treated or punished in a cruel, inhuman or degrading way. However, vestiges of a more punitive and primitive nature still linger in some schools because teachers lack knowledge, skills and the disposition to bring about effective classroom discipline that will instill self-discipline, self-direction and positive attitudes in learners and therefore enhance effective teaching and learning in the contemporary classroom.

The vast majority of teachers do encounter discipline problems, as stressors, both in and outside the classroom. One of the frequent causes of stress in secondary schools are learners disrupting the process of education and low levels of motivation (Payne \& Furnham, 1987 \& Kyriacou, 1987). Hayward (1993) asserts that discipline and classroom control issues cause interpersonal stress for teachers at all grade levels. The study conducted by Marais (1992) found that stress resulting from teachers having to cope with learners' behavioural problems, ranked seventh out of 84 factors.

\subsection{Job insecurity}

The responses with regard to job insecurity are summarized in table 5 (appendix E). Stress arising from job insecurity is concerned with stress arising from changes, insecurity or uncertainty in the teaching profession. This area of stress was represented in the questionnaire by items such as feeling vulnerable to redundancy, constant changes taking place in the teaching profession, fear of being involuntary transferred and lack of promotional opportunities and prevalence of unfair promotional procedures. Table 5 shows that $50.5 \%$ of the respondents reported high to very high levels of stress from job insecurity. Other respondents (32,9\%) reported low to moderate levels of stress and $16,6 \%$ of the respondents reported no stress from this area.

The study established that teachers were mainly stressed due to the following: fear of being voluntary transferred to another school due to rightsizing and Rationalisation (R\&R) or Post Provisioning Norm (PPN), lack of promotional opportunities and prevalence of unfair promotional procedures, constant changes taking place within the teaching 
profession and lack of consultation on how these changes are to be implemented. The longer serving and permanent teachers were found to be less prone to stress related to job insecurity than temporary and inexperienced teachers. This may be attributed to the fact that experienced and permanent teachers are not always affected by involuntary transfers.

In a study conducted by Sidney and Wilmar (1995) results indicate that job insecurity is associated with a deterioration of psychological health (i.e. leading to psychological distress and burnout), as well as job and organisational withdrawal. This therefore has a potential of impacting negatively on the teaching and learning process.

\subsection{Role ambiguity}

The responses with regard to role ambiguity are summarized in table 6 (appendix F). According to Gold and Roth (1993:38) stress arises from role conflict when inappropriate, incompatible and inconsistent demands are placed on teachers. When two or more sets of these inconsistent role behaviors are experienced by the teacher, role conflict results. In particular when the teacher cannot reconcile inconsistencies between these sets of expected role behaviors, they experience role conflict. Table 6 shows that $44,6 \%$ of the respondents reported high to very high levels of stress from role ambiguity. The table also shows that $37,2 \%$ of the respondents fell under the low to moderate stress categories as measured by the life stress scale (LSS). Other respondents $(18,2 \%)$ did not experience any stress from role ambiguity.

Stress in this category emanates from the fact that teachers are expected to provide quality education whilst they are often hindered by unavailability of good learning material. The other reported concern for teachers was that they were held responsible for the decline in discipline among learners in their classes whilst the methods of disciplining children were limited. This could be attributed to the abolition of corporal punishment without providing workable alternative methods of disciplining learners and a lack of support from parents.

The investigation established that when inappropriate, incompatible and inconsistent demands are placed on teachers, they experienced a considerable amount of stress. Role ambiguity was found to be resulting from the following: being unclear on what the scope and responsibilities of one's job were, feeling that one had too little authority to carry out the assigned responsibilities and having to teach a subject or learning area for which one has not been trained. Hayward (1991) and Harden (1999) are of the opinion that role ambiguity plays a part in causing stress. He relates that the concept of role ambiguity has been defined as the lack of clear, consistent information regarding rights, duties and responsibilities. Byme's (1994) view of role ambiguity is associated with a lack of clarity regarding a worker's obligations, rights, objectives, status, and/or accountability. Other contributing factors include increasing complexity of tasks and technology, and continued rapid organizational change.

\subsection{Rapport with management}

The responses with regard to rapport with management are summarized in table 7 (appendix G). This area is concerned with stress arising from interpersonal relationship between the individual teacher and the management and is typified by such items as lack of influence over decision making in the school, having ideas considerably different from those of the principal, poor interpersonal relationship, the list would be longer. Table 7 shows that $49,4 \%$ of the respondents experienced high to very high levels of stress from poor rapport with management. The table also reveals that $34,2 \%$ of the respondents reported low to moderate levels of stress while $16,4 \%$ reported no stress from this area. These respondents reported lack of influence in the running of their schools as a major cause of stress in this area.

With regard to rapport with management, the study revealed that teachers experienced stress due to the lack of influence over decision-making in the school governance, poor interpersonal relationship with school management team. Teachers found teaching within this type of environment to be extremely frustrating.

\subsection{Interpersonal relationships with colleagues}

The responses with regard to relationship with colleagues are summarized in table 8 (appendix H). Stress arising from relationship with colleagues is concerned with tensions within the staff. This area of stress was typified by such items as lack of support from colleagues, criticism from colleagues, poor co-operation and communication among the staff, gossiping in the staff room and group pressure; and poor interpersonal relationships among the staff members.

Table 7.7 indicates that $51,1 \%$ of the respondents reported high to very high levels of stress from tensions within the staff. The table also shows that $36,8 \%$ of the respondents reported low to moderate levels of stress. Other 
respondents $(12,1 \%)$ did not suffer any stress from relationships with colleagues. The study revealed that a substantial number of teachers experienced stress due to poor interpersonal relationships with their colleagues. This included lack of support from colleagues, criticism from colleagues, poor communication and co-operation among the staff.

\subsection{Lack of Rewards and Recognition}

The responses with regard to rewards and recognition are summarized in table 9 (appendix I). This area of stress is concerned with the system of rewards and recognition, or lack of them. This stress arises from the lack of rewards in terms of such considerations as money, status and recognition of personal worth. Table 7 shows that $48,3 \%$ of the respondents reported high to very high levels of stress resulting from lack of rewards and recognition. The table also reveals that $36,8 \%$ of the respondents experienced low to moderate levels of stress while, $14,9 \%$ reported no stress from this area.

The investigation revealed that the fifth highest levels of stress among teachers were found to be those arising from lack of recognition and rewards. This kind of a stressor results from lack of satisfactory rewards in terms of both money and status, lack of recognition of teacher professionalism within and outside the education system, lack of regular feedback about teacher's work and lack of appreciation, respect and consideration by the Department of Education and the wider society. In a study conducted by Smith and Bourke (1992) the highest levels of teacher stress were found to be arising from a lack of reward and recognition and a chance to be promoted.

\subsection{Other Stressors}

The responses with regard to other stressors are summarized in table 10 (appendix J). Other stressors refer to any related stressor that might put pressure on the teacher in his or her working environment. In terms of factors associated with teacher stress, the study revealed that a combination of work-related and external factors was associated with teacher stress. The respondents reported different factors outside their working environment, to have had a negative impact on their job. These included financial and family problems.

Table 7.9 reveals that $51,9 \%$ of the respondents fall into the high to very high stress categories as measured by Life Stress Scale. The investigation also shows that $33,8 \%$ of the respondents reported low to moderate levels of stress. Other respondents $(14,3 \%)$ did not experience any stress from this area of stress. The study found that there were a variety of other stressors, which put pressure on a teacher in his or her work environment. These included crime in schools, teachers being robbed of their valuables and money, poor working conditions and lack of physical resources, personal problems outside the working environment and transportation difficulties in getting to school.

\section{Recommendations}

According to Miller (1979:7) the total elimination of stress in education can never be realized because a world free of stress would be without achievement. Behind every human accomplishment lie worry, frustration and discontent. If one were totally satisfied and free of stress, one would have little motivation to do anything. Stress is therefore a powerful generator of productivity, motivation and creativity whereby teachers can give their best performance. However if stress is not kept on a low level it can become counter productive and limit the abilities of teachers.

In the light of Miller's (1979:7) observation, it becomes clear that one cannot do away with stress but can only control it into acceptable levels. The following recommendations are therefore suggested to assist teachers cope with stress in a productive manner. To reduce sources of work-related stress such as work overload, role ambiguity and conflict, Smith and Bourke (1992:208) suggest the following coping strategies for adoption by both school management and teachers for use in an on-going way.

a) Rationalise or regulate work demands due to preparation, assessment procedures, resource distribution, clarify instructional goals and share the workload.

b) Develop support structures such as time management courses, counseling services. Rodgers (1992:37) sees this as perhaps the most important way in which teacher occupational stress can be reduced.

c) Provide greater consideration of all teacher needs, through more flexible management structures able to provide recognition, rewards and collaborative decision making.

The study revealed that role ambiguity was one of the causes of stress among teachers, which resulted from the lack of clarity about work objectives associated with the role, about work colleagues' expectations of the work role and 
about scope and responsibilities of the job. It is therefore recommended that the school management should let the teachers know exactly how they are being evaluated on their work, how to perform adequately and how they can advance in their job.

According to Cole and Walker (1989:44) individual teachers are responsible for identifying factors which are potential stressors for them, reducing or eliminating the risks, taking steps to avoid stressful situations and reducing stress when it occurs by developing a wide range of stress reducing mechanisms. Teachers need training in conflict resolution skills to develop good working relations with colleagues as well as the knowledge of many stress-reducing mechanisms they can employ to counteract the stress- such as: removing themselves temporarily from stressful situations and focusing on another aspect of the job, having a complete change of activity, such as taking exercise, reading a book or using relaxation techniques. Then they can determine which ones are effective for them individually.

The study revealed that too many changes are taking place in our education system, resulting in high stress levels among teachers. It is recommended that the Department of Education develop strategies to prevent undue stress and burnout through staff development activities, the general organisation and management of the school such as making sure that teachers have the necessary tools to implement new initiatives such as Curriculum and Assessment Policy Statements (CAPS), Integrated Quality Management Systems (IQMS) and others. Teachers should be consulted on changes taking place and they must see themselves as being part and parcel of change and not view change as being imposed on them.

Rapid changes in education systems, with increasing standards of work performance and expectations, requires of all teachers to devise strategies of coping with stress associated with these changes within all our schools. Teachers need to be assisted in their effort to reduce their levels of organisational stress and strain. The study revealed that inexperienced teachers are more prone to stress as compared to experienced teachers. It is recommended that there be an effective orientation of new teachers. In their orientation they should be given an open and realistic description of the typical problems and frustrations to be encountered in the teaching profession. This will help them to formulate acceptable and effective solutions in good time.

The initial and important step in dealing with stress is to be more aware about what makes you feel stressed and how you react. Here are some hints that may help teachers to cope with everyday tensions and anxieties and reduce stress in their lives (Cole and Walker: 1989).

i) Be more acknowledgeable about stress.

ii) Plan ahead and manage time.

iii) Set clear objectives

iv) Know your personal limits

v) Question unreasonable demands

vi) Keep fit and take regular exercises

vii) Eat a balanced diet

viii) Make leisure time

ix) Network and develop support systems

x) Share problems

xi) Get adequate rest and sleep

Schools should create an organizational climate that encourage rather than discourage communication, openness and trust so that individual teachers are able to express their inability to cope, their work related fears and are able to ask for help if needed. Finally, it is important to note that discussion on coping has tended to focus on what teachers can do to mitigate stress as individuals. However, much attention still needs to be given to how schools and the Department of Education can help reduce stress for their teachers by the adoption of those management practices, organizational and administrative arrangements, staff relationships, working conditions and curriculum processes that minimize those sources of stress within the school's control.

\section{Conclusion}

Looking at the findings of the study, it seems that stress and dissatisfaction concepts are interrelated, which means that occupational stress contributes to dissatisfaction, which in turn, lead to high levels of stress. Therefore improving work conditions is essential in order to increase the level of satisfaction of teachers with their work and thus lowering the level of stress. In a nutshell, the findings of the study offer evidence that teachers work under stress caused by work related demands such as major restructuring of the teaching profession within a short period of time. This study therefore 
suggests that ways must be found to ease the work demand; otherwise there may be serious implication for teacher productivity as well as the psychological and physical well being of the individuals.

\section{References}

Bernard M E (1990) Taking the stress out of Teaching. North Blackburn : Griffin Press.

Berry L M and Houston J P (1983) Psychology at work: An introduction to Industrial and organizational psychology. England : Brown and Benchmark Publishers.

Cohen L and Manion L (1989) A guide to teaching practice. London: Routledge

Farber B A (1983) Stress and Burnout in the human services professions. New York : Pergamom Press.

Fletcher B.C and Pyne R L (1982) Levels of reported stressors and strains among school teachers : Some UK data, Educational Review $34,267-268$

Fontana D \& Abouserie A (1993) Stress levels, gender, personality factors in teachers, British Journal of Educational Psychology, 63, pp 261-270

Goodall R and Brown L (1980) Understanding Teacher stress : Action in teacher education, 2 : 17 - 22

Gordon J S (1987) Stress Management, Philadelphia : Chelsea House Publishers.

Glaxton G (1989) Being a teacher : A positive approach to change and stress, London. Biddles L.T.D.

Hodge G M (1992) Teacher stress and burnout: An Investigation of their causes and connections : Paper presented at Australian Teacher Education Association, 22nd Annual Conference, Ballina, N S W.

Khathi L J (1990), An investigation of some socio-educational factors contributing to high failure rate in Matric in KwaZulu Natal, KwaDlangezwa: University of Zululand (M. Ed dissertation)

Kremmer A E \& Hoffman E G (1985) Classroom stress and teacher burnout. Phi Delta Kappan, 2:253

Kyriacow C and Sutcliffe J (1979) A role on teacher stress and locus of control, Journal of occupational psychology, 52, 227 - 228.

Kyriacou, C. (1998). Teacher Stress: Past and present. In J. Dunham \& V. Varma (Eds), Stress in teachers. London: Whurr Publishers

Michael T R (1995) Occupational stress. Hillsdale: NJ Erlbaum

Miller W C (1979) Dealing with stress : A challenge for teachers. PhiDelta Kappan Fast backs, $130: 7$-30

Mullius J L (1996) Management and Organisational behaviour. London : Pitman Publishing Company.

Musikanth S (1996) Stress Matters : Durban : William Waterman Publishers.

Naidoo, E R G (1996) Educational Psychology: An African Perspective, Durban, Butterworths.

Oppenheim, A N (1992), Questionnaire design, Interviewing and attitude measurement, London, Pinter Publishers.

Osipaus S H and Spokane A R (1987) Occupational Stress Inventory. New York : Marathon Consulting Press.

Otto R (1986) Teachers under Stress. Melbourne : Hill of content Publishers.

Payne M A and Furnham A (1987) Dimensions of Occupational Stress in West Indian Secondary school teachers, British Journal of Educational psychology VOL $57,141-150$

Pithers R T \& Forgarty G J (1985) Occupational stress among vocational teachers. British Journal of Educational Psychology 65, 3 - 4 .

Punch K F \& Tutteman E (1990) Correlates of Psychological Distress among secondary school teachers. British Educational Research Journal, Vol. 16, $369-382$

Riches C \& Morgan C (1989) Human management in education. Philadelphia: Open University Press

Rodgers M (1992) Organisation Theory. Boston: Allyn Bacon

Selye H, (1982) The Stress of Life $2^{\text {nd }}$ ed., New York: McGraw Hill.

Sidney W. A., Wilmar B. (1995). The effects of job insecurity on psychological health and withdrawal: A longitudinal study, Australian Psychologist, Volume 30, Issue 1 March 1995. , pages $57-63$

Smith M \& Bourke B T (1992) Human behaviour at work. Washington DC: The Falmer Press.

Sutherland, V. J., \& Cooper, C. L. (2000). Strategic Stress Management. London: Palgrave Publishers, Ltd.

Telfer R \& Swannt T (1986) Teacher motivation on alternative promotion structures for NSW high school, Journal of Education Administration, 24 (1), 38 -57.

Trevers C J \& Cooper C L (1996) Teachers under pressure: Stress in teaching profession. London: Routledge

Tuckman B. W (1994) Conducting Educational Research. Florida : Harcout-Brace College Publishers.

Van der Westhuizen P C (1995) Effective Educational management. Pretoria : Kagiso Tertiary.

Walker W \& Cole M (1989) Teaching and stress. New York: John Willey \& Sons.

Weaver D H and Wilhoit G C (1990) Newsroom guide to polls and surveys, Bloomington :Indiana University Press

Williams, M., \& Gersh, I. (2004). Teaching in mainstream and special schools: are the stresses similar or different? British Journal of Special Education, 31(3): 157-162.

Woodhouse D A, Hall E and Wooster A D (1985) Taking control of stress in teaching, British Journal of Educational psychology 55, 119 123. 


\section{Appendix A}

Table 1: Description of biographical data of participants $(n=168)$

\begin{tabular}{|l|c|c|}
\hline 1. Age in years & $F$ & $\%$ \\
\hline below 30 & 46 & 27 \\
\hline $30-39$ & 63 & 37 \\
\hline $40-49$ & 38 & 23 \\
\hline $50-59$ & 21 & 13 \\
\hline 2. Gender & & \\
\hline Female & 120 & 71 \\
\hline Male & 48 & 29 \\
\hline 3. Teaching experience in years & & \\
\hline 0 - 5 & 37 & 22 \\
\hline $6-10$ & 60 & 36 \\
\hline 11 \& above & 71 & 42 \\
\hline 4. Qualifications & & \\
\hline Matric & 11 & 7 \\
\hline Diploma & 58 & 35 \\
\hline Degree Courses & 27 & 16 \\
\hline Degree (B.Paed, B.A., B.Sc. etc) & 68 & 40 \\
\hline Honours & 4 & 2 \\
\hline B.Ed. & 0 & 0 \\
\hline M.Ed. & 0 & 0 \\
\hline MA/MSc. & 0 & 0 \\
\hline Doctorate & 0 & 0 \\
\hline Others & 0 & 0 \\
\hline 5. Employment Status & & \\
\hline Permanent & 136 & 81 \\
\hline Temporary & 32 & 19 \\
\hline
\end{tabular}

\section{Appendix B}

Table 2: Curriculum changes and related issues $(n=168)$

\begin{tabular}{|c|c|c|c|c|c|c|}
\hline \multirow[b]{2}{*}{ Possible Source of Stress } & \multicolumn{6}{|c|}{ Response Category } \\
\hline & 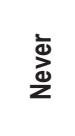 & 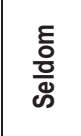 & 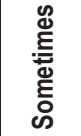 & 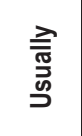 & $\frac{n}{\frac{N}{3}}$ & 퓽 \\
\hline \multirow{2}{*}{$\begin{array}{l}\text { Lack of personal confidence in implementing the National Curriculum } \\
\text { Statement (NCS) due to insufficient training }\end{array}$} & 18 & 19 & 28 & 46 & 57 & 168 \\
\hline & $10.7 \%$ & $11,3 \%$ & $16,7 \%$ & $27,3 \%$ & $34 \%$ & $100 \%$ \\
\hline \multirow{2}{*}{$\begin{array}{l}\text { Having to deal with complex policy document and terminology of } \\
\text { National Curriculum Statement (NCS) }\end{array}$} & 10 & 36 & 30 & 40 & 52 & 168 \\
\hline & $5,9 \%$ & $21,4 \%$ & $17,9 \%$ & $23,8 \%$ & $31 \%$ & $100 \%$ \\
\hline \multirow{2}{*}{ Lack of guidelines on what needs to be learnt on each grade } & 33 & 19 & 28 & 50 & 38 & 168 \\
\hline & $19,6 \%$ & $11,3 \%$ & $16,7 \%$ & $29,8 \%$ & $22,6 \%$ & $100 \%$ \\
\hline \multirow{2}{*}{$\begin{array}{l}\text { Lack of ongoing support for the teachers to address problems which } \\
\text { might have arose }\end{array}$} & 9 & 25 & 44 & 38 & 52 & 168 \\
\hline & $5,4 \%$ & $14,9 \%$ & $6,2 \%$ & $22,6 \%$ & $30,9 \%$ & $100 \%$ \\
\hline \multirow{2}{*}{ Having to use inadequate and poor learning material. } & 23 & 23 & 26 & 54 & \begin{tabular}{|l|}
42 \\
\end{tabular} & 168 \\
\hline & $13,7 \%$ & $13,7 \%$ & $15,5 \%$ & $32,1 \%$ & $25 \%$ & $100 \%$ \\
\hline Overall Total Score & $11.1 \%$ & \multicolumn{2}{|c|}{$33.1 \%$} & \multicolumn{2}{|c|}{$55.8 \%$} & $100 \%$ \\
\hline
\end{tabular}

\section{Appendix C}

Table 3: Time pressure and work overload $(n=168)$ 


\begin{tabular}{|c|c|c|c|c|c|c|}
\hline \multirow[b]{2}{*}{ Possible Source of Stress } & \multicolumn{6}{|c|}{ Response Category } \\
\hline & 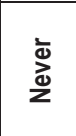 & 흠 & 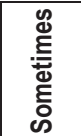 & $\begin{array}{l}\stackrel{\lambda}{\bar{N}} \\
\stackrel{0}{\supset}\end{array}$ & 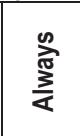 & 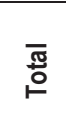 \\
\hline \multirow{2}{*}{ Having to deal with classes of large sizes due to poor teacher pupil ratio } & 31 & 22 & 25 & 42 & 48 & 168 \\
\hline & 18.5 & 13 & 14.9 & 25 & 28.6 & 100 \\
\hline \multirow{2}{*}{ Having too heavy workload, one that you can't possibly finish during school hours } & 19 & 34 & 35 & 46 & 34 & 168 \\
\hline & $11.3 \%$ & $20.2 \%$ & $20.8 \%$ & $27.5 \%$ & $20.2 \%$ & $100 \%$ \\
\hline \multirow{2}{*}{ Having the requirement of the job, impact your personal life } & 28 & 21 & 41 & 49 & 29 & 168 \\
\hline & $16.7 \%$ & $12.5 \%$ & $24.4 \%$ & $29.4 \%$ & $17.2 \%$ & $100 \%$ \\
\hline \multirow{2}{*}{ Being exhausted by daily demands at work } & 16 & 50 & 35 & 39 & 28 & 168 \\
\hline & $9.5 \%$ & $29.8 \%$ & $20.8 \%$ & $23.2 \%$ & $16.7 \%$ & $100 \%$ \\
\hline \multirow{2}{*}{ Being unable to meet deadlines and schedules } & 21 & 36 & 26 & 53 & 32 & 168 \\
\hline & $12.5 \%$ & $21.4 \%$ & $15.5 \%$ & $31.5 \%$ & $19.1 \%$ & $100 \%$ \\
\hline Overall Total Score & $13.7 \%$ & \multicolumn{2}{|c|}{$38.7 \%$} & \multicolumn{2}{|c|}{$47.6 \%$} & $100 \%$ \\
\hline
\end{tabular}

\section{Appendix D}

Table 4: Learner related sources of stress $(n=168)$

\begin{tabular}{|c|c|c|c|c|c|c|}
\hline \multirow[b]{2}{*}{ Possible Source of Stress } & \multicolumn{6}{|c|}{ Response Category } \\
\hline & 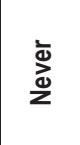 & $\begin{array}{l}\text { 틈 } \\
\text { 을 }\end{array}$ & 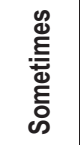 & 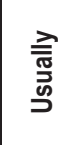 & $\frac{\infty}{\frac{1}{3}}$ & 푱 \\
\hline \multirow{2}{*}{$\begin{array}{l}\text { Having to deal with indiscipline learners who continually misbehave without } \\
\text { support from parents, principals and the Department of education }\end{array}$} & 14 & 42 & 31 & 43 & 38 & 168 \\
\hline & $8.3 \%$ & $25 \%$ & $18.5 \%$ & $25.6 \%$ & $22.6 \%$ & $100 \%$ \\
\hline \multirow{2}{*}{$\begin{array}{l}\text { In adequate disciplinary policy for learners by both school and Department of } \\
\text { Education }\end{array}$} & 30 & 18 & 26 & 42 & 52 & 168 \\
\hline & $17.9 \%$ & $10.7 \%$ & $15.5 \%$ & $25 \%$ & $30.9 \%$ & $100 \%$ \\
\hline \multirow{2}{*}{ Abolition of corporal punishment } & 24 & 28 & 38 & 40 & 38 & 168 \\
\hline & $14.3 \%$ & $16.7 \%$ & $22.6 \%$ & $23.8 \%$ & $22.6 \%$ & $100 \%$ \\
\hline \multirow{2}{*}{ Learners coming to class without necessary learning material } & 22 & 24 & 26 & 45 & 51 & 168 \\
\hline & $13 \%$ & $14.3 \%$ & $15.5 \%$ & $26.8 \%$ & $30.4 \%$ & $100 \%$ \\
\hline \multirow{2}{*}{ Having to deal with learners who are hard to motivate } & 15 & 28 & 31 & 56 & 38 & 168 \\
\hline & $8.9 \%$ & $16.7 \%$ & $18.5 \%$ & $33.3 \%$ & $26.6 \%$ & $100 \%$ \\
\hline Overall Total Score & $12.5 \%$ & \multicolumn{2}{|c|}{$34.8 \%$} & \multicolumn{2}{|c|}{$52.7 \%$} & $100 \%$ \\
\hline
\end{tabular}

\section{Appendix E}

Table 5: Job insecurity $(n=168)$

\begin{tabular}{|c|c|c|c|c|c|c|}
\hline \multirow[b]{2}{*}{ Possible Source of Stress } & \multicolumn{6}{|c|}{ Response Category } \\
\hline & 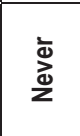 & $\frac{\varepsilon}{\text { 은 }}$ & 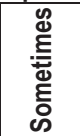 & 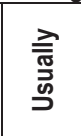 & $\stackrel{\substack{n \\
\frac{\pi}{2}}}{\frac{3}{4}}$ & 퓽 \\
\hline \multirow{2}{*}{ Feeling vulnerable to redundancy or involuntary premature retirement } & 30 & 22 & 37 & 30 & 49 & 168 \\
\hline & $17.9 \%$ & $13 \%$ & $22 \%$ & $17.9 \%$ & $29.2 \%$ & $100 \%$ \\
\hline \multirow{2}{*}{$\begin{array}{l}\text { The constant changes taking place within the teaching profession and lack of } \\
\text { consultation on how these changes are to be implemented }\end{array}$} & 19 & 28 & 20 & 41 & 60 & 168 \\
\hline & $11.3 \%$ & $16.7 \%$ & $11.9 \%$ & $24.4 \%$ & $35.7 \%$ & $100 \%$ \\
\hline \multirow{2}{*}{$\begin{array}{l}\text { Fear of being involuntary transferred to another school due to Right Sizing and } \\
\text { Rationalisation or (R\&R) or Post Provisioning Norm (PPN) }\end{array}$} & 36 & 27 & 25 & 42 & 38 & 168 \\
\hline & $21.4 \%$ & $16.1 \%$ & $14.9 \%$ & $25 \%$ & $22.6 \%$ & $100 \%$ \\
\hline \multirow{2}{*}{$\begin{array}{l}\text { Lack of promotional opportunities and prevalence of unfair promotional } \\
\text { procedures }\end{array}$} & 20 & 18 & 30 & 59 & 41 & 168 \\
\hline & $11.9 \%$ & $10.7 \%$ & $17.9 \%$ & $35.1 \%$ & $34.4 \%$ & $100 \%$ \\
\hline \multirow{2}{*}{$\begin{array}{l}\text { Constant threats by the Minister of Education to weed out dead wood in the } \\
\text { teaching profession }\end{array}$} & 35 & 37 & 32 & 35 & 29 & 168 \\
\hline & $20.8 \%$ & $22 \%$ & $19.2 \%$ & $20.8 \%$ & $17.2 \%$ & $100 \%$ \\
\hline Overall Total Score & 16. \% & \multicolumn{2}{|c|}{$32.9 \%$} & \multicolumn{2}{|c|}{$50.5 \%$} & $100 \%$ \\
\hline
\end{tabular}




\section{Appendix F}

Table 6: Role ambiguity $(n=168)$

\begin{tabular}{|c|c|c|c|c|c|c|}
\hline \multirow[b]{2}{*}{ Possible Source of Stress } & \multicolumn{6}{|c|}{ Response Category } \\
\hline & ऐo & 흥 & 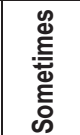 & 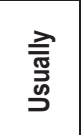 & $\stackrel{\substack{\frac{\pi}{3} \\
\frac{3}{4}}}{2}$ & 푱 \\
\hline \multirow{2}{*}{ Being unclear on just what the scope and responsibilities of your job are. } & 33 & 19 & 28 & 50 & 38 & 168 \\
\hline & $19.6 \%$ & $11.3 \%$ & $16.7 \%$ & $29.8 \%$ & $22.6 \%$ & $100 \%$ \\
\hline \multirow{2}{*}{$\begin{array}{l}\text { Feeling that you have too little authority to carry out the responsibilities } \\
\text { assigned to you }\end{array}$} & 41 & 44 & 30 & 25 & 28 & 168 \\
\hline & $24.4 \%$ & $26.1 \%$ & $17.9 \%$ & $14.9 \%$ & $16.3 \%$ & $100 \%$ \\
\hline \multirow{2}{*}{ Not being able to get information you need to carry out your duties } & 17 & 43 & 49 & 23 & 36 & 168 \\
\hline & $10.1 \%$ & $25.6 \%$ & $29.2 \%$ & $13.7 \%$ & $21.4 \%$ & $100 \%$ \\
\hline \multirow{2}{*}{ Having to teach a subject for which you have not been trained } & 39 & 27 & 18 & 34 & 50 & 168 \\
\hline & $23.2 \%$ & $16.1 \%$ & $10.7 \%$ & $20.2 \%$ & $29.8 \%$ & $100 \%$ \\
\hline \multirow{2}{*}{ Being given extra responsibilities to do } & 23 & 30 & 24 & 32 & 59 & 168 \\
\hline & $13.7 \%$ & $17.9 \%$ & $14.3 \%$ & $19 \%$ & $35.1 \%$ & $100 \%$ \\
\hline Overall Total Score & $18.2 \%$ & \multicolumn{2}{|c|}{$37.2 \%$} & \multicolumn{2}{|c|}{$44.6 \%$} & $100 \%$ \\
\hline
\end{tabular}

\section{Appendix G}

Table 7: Rapport between the teacher and management

\begin{tabular}{|c|c|c|c|c|c|c|}
\hline \multirow[b]{2}{*}{ Possible Source of Stress } & \multicolumn{6}{|c|}{ Response Category } \\
\hline & 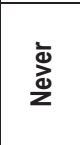 & $\begin{array}{l}\text { 흠 } \\
\text { 읆 }\end{array}$ & 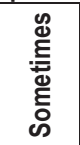 & $\begin{array}{l}\underset{\bar{\Xi}}{\partial} \\
\stackrel{⿹}{\supset}\end{array}$ & $\stackrel{\substack{1 \\
\frac{1}{2}}}{\frac{1}{\alpha}}$ & $\begin{array}{l}\bar{\Phi} \\
\text { 음 }\end{array}$ \\
\hline \multirow{2}{*}{ Lack of influence over decision making in the school governance } & 34 & 19 & 25 & 42 & 48 & 168 \\
\hline & $20.2 \%$ & $11.3 \%$ & $14.9 \%$ & $25 \%$ & $28.6 \%$ & $100 \%$ \\
\hline \multirow{2}{*}{ Having ideas considerably different from those of your principal } & 26 & 22 & 35 & 30 & 55 & 168 \\
\hline & $15.5 \%$ & $13.1 \%$ & $20.8 \%$ & $17.9 \%$ & $32.7 \%$ & $100 \%$ \\
\hline \multirow{2}{*}{$\begin{array}{l}\text { Not knowing what the principal thinks of your performance and how he/she } \\
\text { evaluates it }\end{array}$} & 15 & 17 & 26 & 49 & 61 & 168 \\
\hline & $8.9 \%$ & $10.1 \%$ & $15.5 \%$ & $29.2 \%$ & $36.3 \%$ & $100 \%$ \\
\hline \multirow{2}{*}{$\begin{array}{l}\text { Poor interpersonal relationship with the principal and lack of proper channels of } \\
\text { communication }\end{array}$} & 35 & 21 & \begin{tabular}{|l|}
47 \\
\end{tabular} & 28 & 37 & 168 \\
\hline & $20.8 \%$ & $12.5 \%$ & $28 \%$ & $16.7 \%$ & $22 \%$ & $100 \%$ \\
\hline \multirow{2}{*}{$\begin{array}{l}\text { Having to deal with principal who lacks clear and fair standards for work and } \\
\text { discipline }\end{array}$} & \begin{tabular}{|l|}
28 \\
\end{tabular} & 30 & 22 & \begin{tabular}{|l|}
47 \\
\end{tabular} & 41 & 168 \\
\hline & $16.7 \%$ & $17.9 \%$ & $13 \%$ & $28 \%$ & $24.4 \%$ & $100 \%$ \\
\hline Overall Total Score & $16.4 \%$ & \multicolumn{2}{|c|}{$34.2 \%$} & \multicolumn{2}{|c|}{$49.4 \%$} & $100 \%$ \\
\hline
\end{tabular}

\section{Appendix $\mathrm{H}$}

Table 8: The relationship between the teacher and colleagues. $(n=168)$

\begin{tabular}{|c|c|c|c|c|c|c|}
\hline \multirow[b]{2}{*}{ Possible Source of Stress } & \multicolumn{6}{|c|}{ Response Category } \\
\hline & ऐ) & $\frac{E}{\text { 음 }}$ & 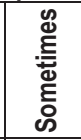 & 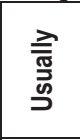 & 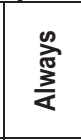 & $\begin{array}{l}\bar{\pi} \\
\text { 으 }\end{array}$ \\
\hline \multirow{2}{*}{ Lack of support from the colleagues } & 23 & 27 & 41 & 31 & 46 & 168 \\
\hline & $13.7 \%$ & $16.1 \%$ & $24.4 \%$ & $18.5 \%$ & $27.3 \%$ & $100 \%$ \\
\hline \multirow{2}{*}{ Poor interpersonal relationship among the staff members } & 17 & 39 & 23 & 56 & 33 & 168 \\
\hline & $10.1 \%$ & $23.2 \%$ & $14.7 \%$ & $33.3 \%$ & $19.7 \%$ & $100 \%$ \\
\hline \multirow{2}{*}{ Gossiping in the staff room and group pressures } & 23 & 18 & 48 & 30 & 49 & 168 \\
\hline & $13.7 \%$ & $10.7 \%$ & $28.6 \%$ & $17.9 \%$ & $29.1 \%$ & $100 \%$ \\
\hline \multirow{2}{*}{ Criticism from the colleagues } & 15 & 26 & 34 & 38 & 55 & 168 \\
\hline & $8.9 \%$ & $15.5 \%$ & $20.2 \%$ & $22.6 \%$ & $32.8 \%$ & $100 \%$ \\
\hline
\end{tabular}




\begin{tabular}{|c|c|c|c|c|c|c|}
\hline \multirow{2}{*}{ Poor communication and co-operation among the staff } & 24 & 18 & 35 & 41 & 50 & 168 \\
\cline { 2 - 6 } & $14.3 \%$ & $10.7 \%$ & $20.8 \%$ & $24.4 \%$ & $29.8 \%$ & $100 \%$ \\
\hline Overall Total Score & $12.1 \%$ & $36.8 \%$ & $51.1 \%$ & $100 \%$ \\
\hline
\end{tabular}

\section{Appendix I}

Table 9: Responses of teachers on rewards and recognition $(n=168)$

\begin{tabular}{|c|c|c|c|c|c|c|}
\hline \multirow[b]{2}{*}{ Possible Source of Stress } & \multicolumn{6}{|c|}{ Response Category } \\
\hline & $\frac{\text { ऐ }}{2}$ & 흥 & 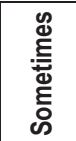 & 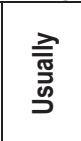 & $\frac{\substack{0 \\
\frac{\pi}{2}}}{4}$ & 흉 \\
\hline \multirow{2}{*}{ Lack of satisfactory rewards in terms of both money and status } & 20 & 26 & 37 & 29 & 56 & 168 \\
\hline & $12 \%$ & $15.5 \%$ & $22 \%$ & $17.2 \%$ & $33.3 \%$ & $100 \%$ \\
\hline \multirow{2}{*}{$\begin{array}{l}\text { Lack of recognition of teachers professionalism within and outside the } \\
\text { education system }\end{array}$} & 40 & 24 & 34 & 31 & 39 & 168 \\
\hline & $23.8 \%$ & $14.3 \%$ & $20.2 \%$ & $18.5 \%$ & $23.2 \%$ & $100 \%$ \\
\hline \multirow{2}{*}{$\begin{array}{l}\text { Lack of appreciation, respect and consideration by the Department of } \\
\text { Education and the wider society }\end{array}$} & 30 & 22 & 38 & 29 & 49 & 168 \\
\hline & $18 \%$ & $13 \%$ & $22.6 \%$ & $17.2 \%$ & $29.2 \%$ & $100 \%$ \\
\hline \multirow{2}{*}{ Lack of regular feedback about your work } & 11 & 43 & 27 & 47 & 40 & 168 \\
\hline & $6.5 \%$ & $25.5 \%$ & $16.1 \%$ & $28 \%$ & $23.9 \%$ & $100 \%$ \\
\hline \multirow{2}{*}{ Inadequate salary increase } & 24 & 19 & 40 & 28 & 57 & 168 \\
\hline & $14.3 \%$ & $11.3 \%$ & $23.8 \%$ & $16.7 \%$ & $33.9 \%$ & $100 \%$ \\
\hline Overall Total Score & $14.9 \%$ & \multicolumn{2}{|c|}{$36.8 \%$} & \multicolumn{2}{|c|}{$48.3 \%$} & $100 \%$ \\
\hline
\end{tabular}

\section{Appendix J}

Table 10: Other stressors associated with teacher stress $(n=168)$

\begin{tabular}{|c|c|c|c|c|c|c|}
\hline \multirow[b]{2}{*}{ Possible Source of Stress } & \multicolumn{6}{|c|}{ Response Category } \\
\hline & $\begin{array}{l}\text { ऐे } \\
\text { ऐ্ }\end{array}$ & 흠 & 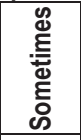 & 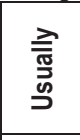 & 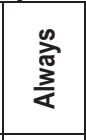 & $\begin{array}{l}\text { त्ञ } \\
\text { 음 }\end{array}$ \\
\hline \multirow{2}{*}{ Crime in schools, teacher being robbed of their valuables and money } & 19 & 20 & 27 & 42 & 60 & 168 \\
\hline & $11.3 \%$ & $11.9 \%$ & $16.1 \%$ & $25 \%$ & $35.7 \%$ & $100 \%$ \\
\hline \multirow{2}{*}{ Lack of safety in schools } & 25 & 37 & 21 & 36 & 49 & 168 \\
\hline & $14.9 \%$ & $22 \%$ & $12.5 \%$ & $21.4 \%$ & $29.2 \%$ & $100 \%$ \\
\hline \multirow{2}{*}{ Poor working conditions and lack of physical resources and funds } & 30 & 42 & 15 & 37 & 44 & 168 \\
\hline & $17.9 \%$ & $25 \%$ & $8.9 \%$ & $22 \%$ & $26.2 \%$ & $100 \%$ \\
\hline \multirow{2}{*}{ Personal problems outside the working environment } & 18 & 24 & 39 & 31 & 56 & 168 \\
\hline & $10.7 \%$ & $14.3 \%$ & $23.2 \%$ & $18.5 \%$ & $33.3 \%$ & $100 \%$ \\
\hline \multirow{2}{*}{ Transportation difficulties in getting to school } & 28 & 30 & 29 & 39 & 42 & 168 \\
\hline & $16.7 \%$ & $17.9 \%$ & $17.2 \%$ & $23.2 \%$ & $25 \%$ & $100 \%$ \\
\hline Overall Total Score & $14.3 \%$ & \multicolumn{2}{|c|}{$33.8 \%$} & \multicolumn{2}{|c|}{$51.9 \%$} & $100 \%$ \\
\hline
\end{tabular}

